\title{
Modeled winter sea ice variability and the North Atlantic Oscillation: a multi-century perspective
}

\author{
Courtenay Strong · Gudrun Magnusdottir
}

Received: 15 August 2008/Accepted: 2 March 2009/Published online: 20 March 2009

(C) The Author(s) 2009. This article is published with open access at Springerlink.com

\begin{abstract}
The relationship between winter sea ice variability and the North Atlantic Oscillation (NAO) is examined for the time period 1860-2300. This study uses model output to extend recently reported observational results to multicentury time scales. Nine ensemble members are used in two Global Climate Models with forcing evolving from preindustrial conditions through the so-called A1B scenario in which carbon dioxide stabilizes at $720 \mathrm{ppm}$ by 2100 . Throughout, the NAO generates an east-west dipole pattern of sea ice concentration (SIC) anomalies with oppositely signed centers of action over the Labrador and Barents Seas. During the positive polarity of the NAO, SIC increases over the Labrador Sea due to wind-driven equatorward advection of ice, and SIC decreases over the Barents Sea due to winddriven poleward transport of heat within the mixed layer of the ocean. Although this NAO-driven SIC variability pattern can always be detected, it accounts for a markedly varying fraction of the total sea ice variability depending on the strength of the forced sea ice extent trend. For the first half of the 20th century or 1990 control conditions, the NAO-driven SIC pattern accounts for almost a third of the total SIC variance. In the context of the long term winter sea ice retreat from 1860 to 2300, the NAO-driven SIC pattern is robustly observable, but accounts for only $2 \%$ of the total SIC variance. The NAO-driven SIC dipole retreats poleward with the retreating marginal ice zone, and its Barents Sea center of action weakens. Results presented here underscore the idea that the NAO's influence on Arctic climate is robustly observable, but time dependent in its form and statistical importance.
\end{abstract}

C. Strong $(\bowtie) \cdot$ G. Magnusdottir

University of California, Irvine, Irvine,

CA 92697, USA

e-mail: cstrong@uci.edu
Keywords Sea ice $\cdot$ North Atlantic Oscillation . Annular mode $\cdot$ Climate change $\cdot$ Global warming

\section{Introduction}

Two patterns of boreal winter sea ice variability are emerging as important based on the past few decades of observations: (1) a downward trend in total sea ice extent that appears to be anthropogenic (Johannessen et al. 2004) and accelerating (Comiso 2006; Serreze et al. 2007), and (2) interannual variations in sea ice motion and concentration that are closely tied to the North Atlantic Oscillation (NAO) or its more hemispheric counterpart the Northern Annular Mode (NAM, also called Arctic Oscillation). Outside the winter season, observed sea ice variability may be more closely tied to the NAM than the NAO (Wang and Ikeda 2000), but the winter manifestations of these patterns over the Atlantic are similar. During winter, an important mode of NAO-driven sea ice variability is a dipole pattern of sea ice concentration anomalies with oppositely-signed centers of action over the Labrador and Barents Seas (Deser and Teng 2008, and references therein). Sea ice extent over the Barents Sea decreases during the positive NAO/NAM and, from the 1960s through the mid 1990s, an increasing trend in the NAM appeared to amplify the rate of winter sea ice retreat (Deser 2000; Venegas and Mysak 2000; Rigor et al. 2002; Hu et al. 2002; Liu and Curry 2004; Rothrock and Zhang 2005; Ukita et al. 2007). Since the mid 1990s, the NAM trend has reversed, and sea ice extent has continued to decline while retaining a measurable signature of forcing by atmospheric circulation variability (Comiso 2006; Maslanik et al. 2007; Francis and Hunter 2004; Deser and Teng 2008). 
The finding that a downward trend is playing an increasingly important role in the spatiotemporal variability of sea ice since the mid 1990s suggests that the prominence of the NAO's imprint on sea ice variability may change over time with sensitivity to how quickly atmosphere and ocean heat content are changing. In addition to variations in radiative forcing, several other factors could account for temporal variations in the synchronization of the NAO and sea ice. First, modeling studies show that ice dynamics and thermodynamics are both active in linking sea ice variability and the NAM or NAO (Zhang et al. 2000), and changes in sea ice growth and melt are driven by, and feedback negatively on, transport-driven changes in sea ice volume (Zhang et al. 2003). There is also a negative feedback between the ice and atmosphere whereby the sea ice patterns associated with the positive polarity of the NAO or NAM can in turn generate a negative NAO-like atmospheric response (Magnusdottir et al. 2004; Deser et al. 2004; Alexander et al. 2004; Kvamsto et al. 2004; Deser et al. 2007). On longer time scales, evidence has been presented to support the existence of feedback processes accounting for decadal cycles in Arctic and subarctic sea ice and sea level pressure (Mysak and Venegas 1998), Finally, Arctic sea ice can be strongly forced on multi-decadal time scales by phenomena in part external to the NAO such as the thermohaline circulation (e.g., Dai et al. 2005) or meridional overturning circulation (Jungcalus et al. 2005).

The idea that the strength of the NAO's influence on Arctic sea ice variability varies over time has been presented in observational studies looking at sea ice extent over various basins (e.g., Vinje 2001; Sorteberg and Kvingedal 2006). Concerning sea ice motion, sea ice export through the Fram Strait is strongly correlated with the NAO/NAM for portions of the observational record (Kwok and Rothrock 1999; Dickson et al. 2000; Kwok 2000), but it has been argued that such correlations are period-dependent based on further study of the observational record (Hilmer and Jung 2000; Vinje 2001; Cavalieri 2002) and modeling work (Jung and Hilmer 2001). Goose and Holland (2005) used surface air temperature as a more general measure of Arctic climate in a long control integration of the NCAR Community Climate System Model, and also found evidence of a time-varying NAO influence. Concerning the last several decades, wind-driven sea ice velocities evidently played a key role in downward sea ice extent trends toward the end of the 20th century, while longer-term steady declines in sea ice extent were related to increasing air temperatures (Rothrock and Zhang 2005; Lindsay and Zhang 2005). Enhanced radiative forcing associated with rising greenhouse gas concentrations is projected to continue thinning the winter sea ice extent over the next century (Zhang and Walsh 2006; Arzel et al.
2006; Serreze et al. 2007), and there may be contemporaneous trends in the NAO (Stephenson et al. 2006) and NAM (Miller et al. 2006).

Collectively, the studies above evidence a clear role for the NAO in recently observed winter sea ice variability, but raise questions about the overall importance, or perhaps even existence, of NAO-driven sea ice variability on longer time scales. The sea ice edge was well positioned over the past few decades to respond to NAO-driven variability, but preceding or projected future climate states could physically decouple the sea ice edge from NAO-driven circulation and temperature anomalies, and such a change would have implications for NAO-sea ice interaction and feedback processes. The present study was undertaken to test for the presence of an NAO-driven pattern of sea ice variability in available climate simulations running from pre-industrial times through 2300 , and to determine how any identified patterns might change or disappear under the projected retreat of the sea ice edge. For the 1860-2300 time period, we show that an NAO-driven sea ice variability pattern is (1) always discernible, (2) evolves with the retreating sea ice edge, and (3) accounts for a markedly varying fraction of the total sea ice variability depending on the strength of the forced sea ice extent trend. Methods and model output are described in Sect. 2, results are organized by time periods in Sect. 3, and a summary and discussion are given in Sect. 4.

\section{Models and methods}

\subsection{Models}

We analyze an ensemble of fully coupled global climate model runs prepared for the Intergovernmental Panel on Climate Change Assessment Report 4 (IPCC AR4) by the National Center for Atmospheric Research (NCAR) and the Max Planck Institute for Meteorology (MPI). The MPI ensemble members were generated using the European Centre Hamburg Model (ECHAM) version 5 (Jungcalus et al. 2006), and the NCAR members were generated using the Community Climate System Model (CCSM) version 3 (Meehl et al. 2006). Each member branched from a different point in a pre-industrial control run, continued forward under presumed historical forcing through 1999 (the "climate of the 20th century experiments"), and then continued through at least 2099 following the forcing specified by the IPCC A1B scenario which stabilized $\mathrm{CO}_{2}$ concentration at $720 \mathrm{ppm}$ by the year 2100 (Nakicenovic and Swart 2000). Reliable prediction of sea ice is challenging because of the large natural variability inherent in the Arctic, and discrepancies between observations and ensemble-based sea ice 
Table 1 Model runs used in the analysis

\begin{tabular}{|c|c|c|c|c|c|}
\hline Model & Resolution & Levels & Top & Member & Years \\
\hline \multirow[t]{2}{*}{ ECHAM5 } & T63 & 31 & $10 \mathrm{hPa}$ & ECHAM $_{a, c}$ & $1860-2200$ \\
\hline & & & & $\mathrm{ECHAM}_{\mathrm{b}}$ & $1860-2300$ \\
\hline \multirow[t]{2}{*}{ CCSM3 } & $\mathrm{T} 85$ & 26 & $2.2 \mathrm{hPa}$ & $\mathrm{CCSM}_{\mathrm{a}-\mathrm{e}}$ & 1900-2099 \\
\hline & & & & $\mathrm{CCSM}_{1990}$ & Perpetual 1990 \\
\hline
\end{tabular}

projections have been documented (e.g., Stroeve et al. 2007). Nonetheless, the AR4 versions of ECHAM and CCSM are among the models generating present day sea ice extent and seasonal cycles in reasonable agreement with observations (Parkinson et al. 2006; Zhang and Walsh 2006; Eisenman et al. 2007), and results specific to the analyses we present here are largely consistent across the models and ensemble members we examined.

As summarized in Table 1, we analyzed a total of eight ensemble members that span the climate of the 20th century and the A1B scenario through at least 2099, and denote each member with the model name and a subscript. $\mathrm{CCSM}_{\mathrm{d}}$, for example, is the fourth ensemble member (alphabetically) in the NCAR experiments. The ECHAM members continue through 2200 or 2300 and we consider the ECHAM E $_{\mathrm{b}}$ run over its entire 1860-2300 duration in the Sect. 3.4. We also analyze years 100-599 of a 700-year CCSM control run at 1990 conditions (CCSM 1990$)$. All ensemble members were obtained from the Earth System Grid at http://www.earthsystemgrid.org.

We base our results on January-March (JFM) mean values in order to capture the part of winter when the NAO is well-defined and the beginning of the spring season when sea ice is of maximum extent. Our primary variables are sea ice concentration (SIC) and sea-level pressure (SLP). For the $\mathrm{CCSM}_{1990}$ run, we analyze several additional variables to explore the causes of observed sea ice variations. Specifically, we analyze heat flux integrated over the depth of the oceanic mixed layer $\mathbf{F}=\left(F_{x}, F_{y}\right)$. We also consider sea ice velocity and two rates of sea ice growth: basal and frazil, where basal refers to thickening of sea ice from below and frazil refers to the formation of new ice crystals not necessarily at the surface of the ocean. Finally, the sea ice model of CCSM partitions the rate of change of sea ice area into a component due to thermodynamics and a component due to dynamics, denoted respectively $\left(\partial a_{i} / \partial t\right)_{T}$ and $\left(\partial a_{i} / \partial_{t}\right)_{D}$.

\subsection{Methods}

To obtain the empirical orthogonal functions (EOFs) of a scalar field, we weight the time-by-location data table by the square root of the grid cell area and calculate the unit- length eigenvectors of the location-by-location covariance matrix. The square root of the grid cell areas are used rather than the square root of the cosine of latitude because some of the grids are centered on Greenland. We refer to the eigenvectors as loading patterns or EOFs and refer to the associated expansion coefficients as principal components. For display purposes, all principal components are standardized as $Z$-scores, meaning that each time series has zero mean and unit standard deviation. Where we display the average EOF across several ensemble members, the average EOF is scaled to unit length. For the vector field $\mathbf{F}$, we found that complex and real-vector EOF analyses (Kaihatu et al. 1998) produced similar results and show the real-vector EOFs here to circumvent the ambiguity in the direction of the eigenstructures inherent in the complex EOFs.

We define the NAO as the leading EOF of JFM mean SLP over the domain $20^{\circ}-80^{\circ} \mathrm{N}$ and $90^{\circ} \mathrm{W}-40^{\circ} \mathrm{E}$ (Hurrell 1995). We refer to the NAO's principal component as the NAO index (NAOI). It will be necessary to examine more than one SIC EOF, so we use SIC with a subscript $i$ to denote the $i$ th EOF and remove the bold font when referring to the associated principal component. For example, the second EOF of sea ice concentration is $\mathbf{S I C}_{2}$ and its principal component is $\mathrm{SIC}_{2}$.

Correlations are reported as significant if they pass a $95 \%$ confidence level test using an effective sample size $n^{\prime} \equiv n\left(1-\rho_{1}\right) /\left(1+\rho_{1}\right)$, where $\rho_{1}$ is the lag- 1 autocorrelation coefficient. For the correlation between a vector and scalar field, we calculate the Pearson correlation $(r)$ of the scalar with each vector component separately. Using the NAOI and $\mathbf{F}$ as an example, these correlation coefficients are used to define a "correlation vector" $\mathbf{r}$ at each grid point

$\mathbf{r} \equiv\left(r\left(F_{x}, N A O I\right), r\left(F_{y}, N A O I\right)\right)$.

Given the field of $\mathbf{r}$, we map arrows with length equal to the magnitude of $\mathbf{r}$ and direction everywhere tangent to $\mathbf{r}$.

\section{Results}

Since our aim is to explore the time varying relationship between the NAO and sea ice in winter, we present our results in sections covering specific time periods: the early 20 th century, the 21 st century, the 22 nd century, and the multi-century period 1860-2300. For these various blocks of time, the NAO undergoes some variations and the NAOI has some time-dependent trends, but the NAO is consistent relative to the large variations in the sea ice EOFs. The NAO accounts for between $41 \%$ and $46 \%$ of the total SLP variance within the NAO domain for all the time periods we consider. 


\subsection{First half of 20th century}

To present the basic form of the relationship between the NAO and SIC, we begin with the first half of the "climate of the 20th century experiment." As we will later show, this is a time when SIC is most clearly dominated by NAOrelated variability. Panels a and c of Fig. 1 show the NAO and SIC $_{1}$ averaged across the ECHAM $_{a-c}$ and CCSM $_{a-e}$ ensemble members respectively for 1901-1950. The SIC 1 composites feature an east-west dipole of SIC with oppositely-signed centers of action over the Labrador and Barents Seas. SIC 1 accounts for between a quarter and a third of the total North Atlantic SIC variance. These patterns are similar to those found in observations for the latter part of the 20th century (Deser 2000), and similar to results from the $\mathrm{CCSM}_{1990}$ control simulation (Fig. 1e). The Labrador Sea center of action in the CCSM $_{a-e} \mathbf{S I C}_{1}$ composite extends farther eastward into the Atlantic than in the $\mathrm{CCSM}_{1990}$ and $\mathrm{ECHAM}_{\mathrm{a}-\mathrm{c}}$ results-a phenomenon that will be discussed toward the end of this section.

Examples of $\mathrm{SIC}_{1}$ from certain ensemble members are shown in Fig. 1b, d, f along with the corresponding NAOI. The significant correlations $r\left(\mathrm{SIC}_{1}, N A O I\right)$ can be understood broadly by considering the pressure changes associated with the positive and negative polarities of the NAO. When the NAO is positive, SLP is decreased over the northern center of action, which supports anomalously equatorward advection of cold air and sea ice over the western North Atlantic and anomalously poleward advection of warm air, sea ice, and oceanic heat over the eastern North Atlantic.

To explore in more detail why these NAO-driven advection patterns support an east-west SIC dipole, we consider correlations between the NAOI and several model output fields from $\mathrm{CCSM}_{1990}$. Figure 2a depicts key dynamic processes and Fig. $2 \mathrm{~b}$ shows key thermodynamic processes. Beginning with the dynamic processes, the positive NAO means decreased SLP over the subpolar Atlantic. The associated cyclonic surface wind anomalies support a cyclonic pattern of sea ice velocity anomalies that advect sea ice out of the Barents Sea into the high Arctic and from the Canadian Arctic Archipelago into the Labrador Sea (arrows, Fig. 2a). These NAO-driven patterns of sea ice advection contribute to changes in sea ice area due to dynamics $\left(\partial a_{i} / \partial t\right)_{D}$ (shading, Fig. 2a). Where sea ice velocities cause divergence of existing sea ice
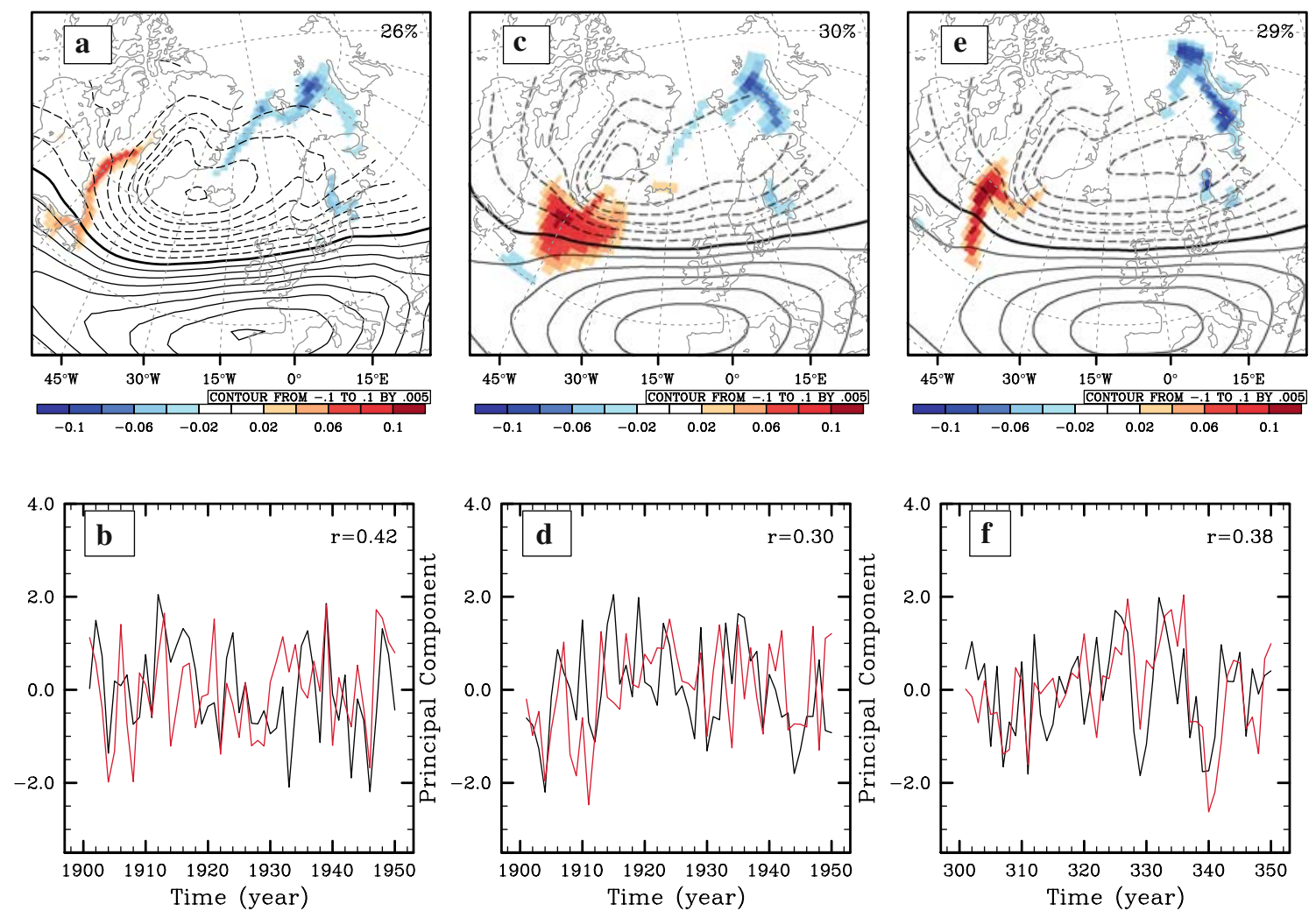

Fig. 1 For years 1901-1950. a The leading EOF of sea ice concentration (shading) and sea-level pressure (contours) averaged across ECHAM $_{a-c}$. b The associated principal components (PCs) from $\mathrm{ECHAM}_{\mathrm{b}}$ (sea-level pressure is red). c, d Same but for $\mathrm{CCSM}_{\mathrm{a}-\mathrm{e}}$ with PCs from $\mathrm{CCSM}_{\mathrm{c}}$. e, f Same but for years 100-599 of
$\mathrm{CCSM}_{1990}$ with a portion of the full PC time series shown. As in all subsequent figures, any percentages shown in the upper right are the fraction of total variance accounted for by the depicted sea ice EOF and a displayed Pearson correlation $(r)$ means the depicted time series are significantly correlated 
$\left(\partial a_{i} / \partial t\right)_{D}$ is negative, such as along the Eurasian arctic coast and the coast of the Labrador Sea. Conversely, regions of sea ice convergence have positive $\left(\partial a_{i} / \partial_{t}\right)_{D}$, such as along the Canadian Arctic coast, the central Labrador sea, and the Irminger Basin.

Considering thermodynamic processes, the positive NAO is associated with marked changes in the transport of heat in the North Atlantic, which has implications for the formation and melting of sea ice. Deser (2000) illustrated and discussed the role of surface air temperature in the NAO-driven sea ice dipole using observations. Considering oceanic processes, during the positive NAO poleward heat transport within the oceanic mixed layer $(\mathbf{F})$ is anomalously high along the Norwegian coast into the Nordic seas (arrows, Fig. 2b), resulting in depressed basal ice growth rates throughout the marginal ice zone east of Greenland and in the Barents Sea (shading, Fig. 2b). Conversely, oceanic heat anomalies are directed out of the Labrador Sea during the positive NAO (arrows, Fig. 2a), and basal ice growth rates are enhanced within Baffin Bay and along the coastal Labrador Sea (shading, Fig. 2b). The overall sense of the NAO-driven heat flux anomalies (arrows, Fig. 2b) is consistent with the observational study of Flatau et al. (2003) which found that a positive NAO was associated with stronger northeastward directed flow in the North Atlantic Current and a more intense cyclonic gyre in the Irminger Basin. Let us summarize the dynamic and thermodynamic processes by which the NAO supports an east-west sea ice dipole. Over the western North Atlantic, the positive NAO is associated with increased basal sea ice growth and increased sea ice advection into the Labrador Sea. Over the eastern North Atlantic, the positive NAO is associated with decreased basal sea ice growth and increased sea ice advection out of the Barents Sea.

We now return to the anomalously large east-west extent of the positive center of action in the composite $\mathbf{S I C}_{1}$ for $\mathrm{CCSM}_{\mathrm{a}-\mathrm{e}}$ (Fig. 1c), and note that this is common to all the ensemble members. It is useful to compare the $\mathrm{CCSM}_{\mathrm{a}-\mathrm{e}}$ and $\mathrm{CCSM}_{1990}$ results since the only difference between the runs is the external forcing-the model physics and flux parameterization are otherwise identical. Note that the negative center of action of the NAO is shifted west in the $\operatorname{CCSM}_{a-e}$ result relative to the same center in the $\mathrm{CCSM}_{1990}$ result (compare dashed contours in Fig. 1c, e). A stronger negative center in the NAO would be consistent with stronger wind-driven sea ice advection into the waters south of Greenland.

\subsection{The 21 st century}

Moving ahead to the 21 st century, the NAO-driven eastwest SIC dipole described in the previous section is a less prominent pattern of SIC variability. For years 2001-2099 in ECHAM $_{a-c}$ and CCSM $_{a-e}, \mathbf{S I C}_{1}$ is a single-signed EOF distributed across the entire marginal ice zone, accounting for the majority of the North Atlantic SIC variance (Fig. 3a, b). As an example of the associated principal component, we show $\mathrm{SIC}_{1}$ from $\mathrm{CCSM}_{\mathrm{c}}$ in Fig. 3c. The upward trend in $\mathrm{SIC}_{1}$ indicates a loss of ice over the marginal ice zone, and this loss is well correlated with oceanic flux of heat into the North Atlantic. To illustrate this, we show the leading EOF of $\mathbf{F}$ in Fig. $3 b$ (arrows) and its associated principal component in Fig. 3c (red curve). The leading $\mathbf{F}$ EOF traces two primary heat transport patterns: (1) poleward $\mathbf{F}$ from west of the British Isles, up the coast of Norway and into the Barents Sea and (2) equatorward $\mathbf{F}$ along the east coast of Greenland and into the Labrador Sea. Intensification of these heat transport patterns is consistent with the loss of ice in the marginal ice zone indicated by SIC $_{1}$ and its principal component.

The NAO-driven east-west dipole of SIC described in the previous section appears in slightly modified form as SIC ${ }_{2}$ during 2001-2099 (Fig. 3d, e). Relative to the early 20th century results, the Labrador Sea center of action is
Fig. 2 Both panels are for $\mathrm{CCSM}_{1990}$ and show the loading pattern of the NAO (contours). a The correlation between sea ice velocity and the NAO (arrows), and the correlation between $\left(\partial a_{i} / \partial t\right)_{D}$ and the NAO (shading). b The correlation between $\mathbf{F}$ and the NAO (arrows), and the correlation between basal sea ice growth rate and the NAO (shading)
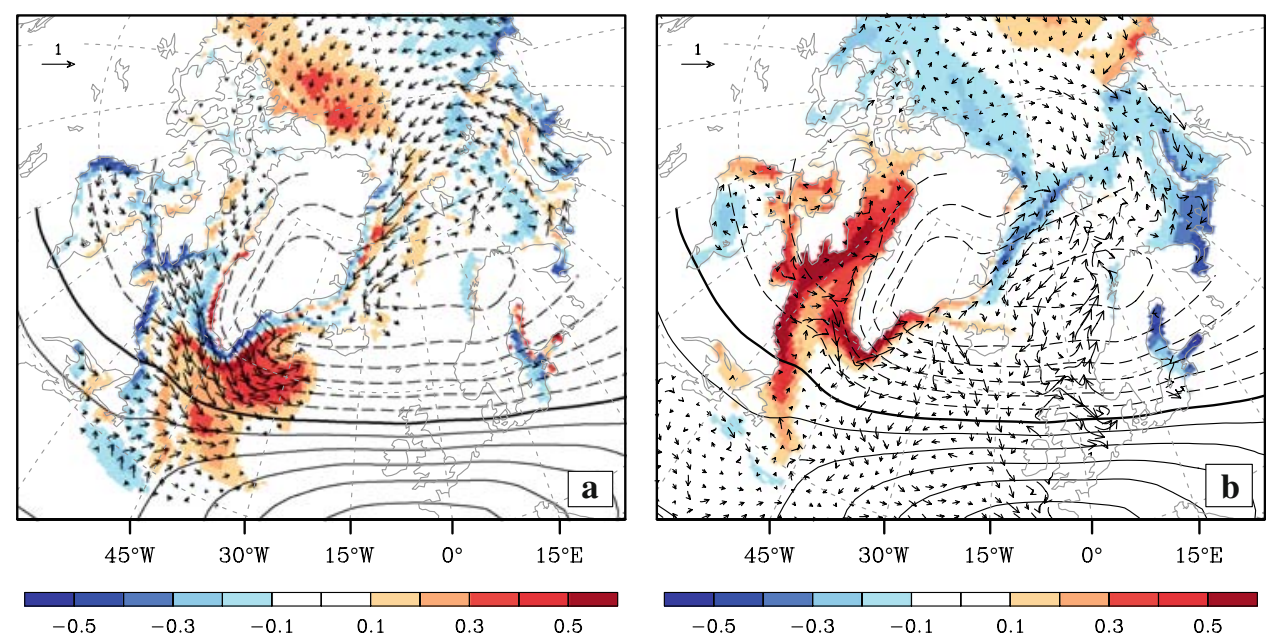

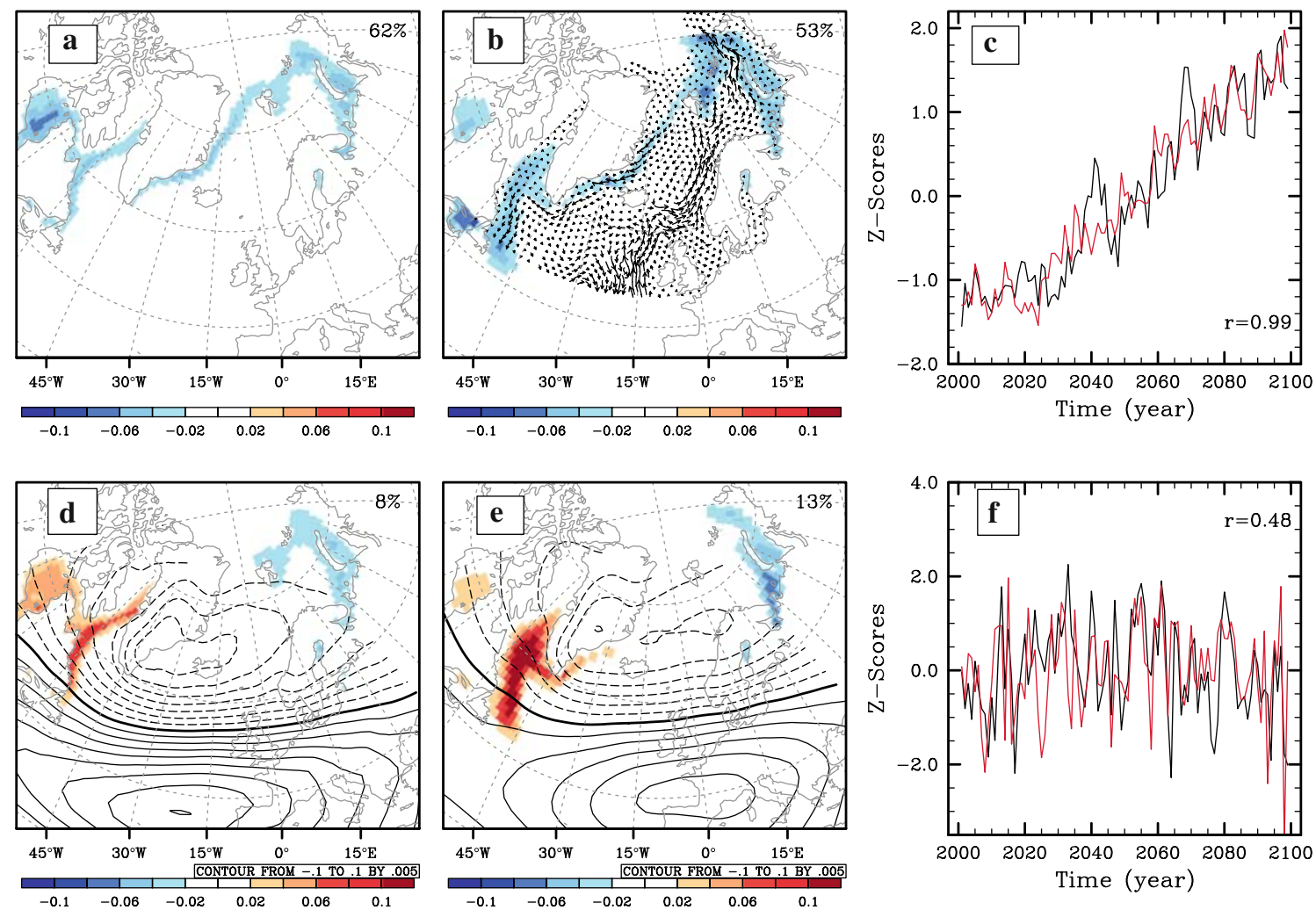

Fig. 3 All panels are for years 2001-2099. a The leading EOF of sea ice concentration averaged across $\mathrm{ECHAM}_{\mathrm{a}-\mathrm{c}}$. b The leading EOF of sea ice concentration averaged across $\mathrm{CCSM}_{\mathrm{a}-\mathrm{e}}$ (shading) and the leading EOF of $\mathbf{F}$ for $\mathrm{CCSM}_{\mathrm{a}}$ (arrows). $\mathbf{c}$ Principal components (PCs) from panel $b$ corresponding to ensemble member $\operatorname{CCSM}_{\mathrm{a}}$ (the $\mathbf{F}$ PC is

red). d The loading pattern of the NAO (contours) and the second EOF of sea ice concentration (shading) averaged across ECHAM $_{\mathrm{a}-\mathrm{c}}$. e Same as panel $d$ but for $\mathrm{CCSM}_{\mathrm{a}-\mathrm{e}}$. f The PCs associated with the EOFs in panel $e$ for ensemble member $\mathrm{CCSM}_{\mathrm{e}}$

retreated northwestward, particularly for the $\mathrm{CCSM}_{\mathrm{a}-\mathrm{e}}$ ensemble, and the Barents Sea center of action is shifted eastward across Novaya Zemlya. The $\mathrm{SIC}_{2}$ expansion coefficient from each ensemble member is well-correlated with its corresponding NAOI (e.g., Fig. 3f), but these patterns account for only $8-13 \%$ of the total North Atlantic SIC variance. The decline in SIC over the marginal ice zone dominates the variability. Interestingly, the $\mathbf{S I C}_{2}$ patterns account for approximately a quarter of the residual variance that remains after accounting for $\mathbf{S I C}_{1}$, which is similar to the proportion of variance accounted for by NAO-driven east-west SIC dipoles in the 20th century runs and the 1990 control run. In other words, if the SIC loss pattern across the marginal ice zone is removed from the SIC covariance structure, the NAOdriven east-west dipole pattern consistently accounts for about a quarter to a third of the North Atlantic SIC variance.

An increasing body of literature is supporting the idea of a time-dependent influence of the NAO on sea ice concentration variability as outlined in the Introduction. We support that idea here by considering how the prominence of NAO-driven SIC patterns varies over the 20th to 23rd centuries. To accomplish this, we calculate the NAO, $\mathbf{S I C}_{1}$, and $\mathbf{S I C}_{2}$ for sliding 40-year windows centered at ten year intervals, and examine the correlation between the calculated principal components. We show the results of this analysis in Fig. 4. From 1900 to 2150, the correlation $r\left(\mathrm{SIC}_{1}, \mathrm{NAOI}\right)$ generally decreased while the correlation $r\left(\mathrm{SIC}_{2}, \mathrm{NAOI}\right)$ generally increased. The sense of these changes are shown by the least squares regression lines in Fig. 4. Visually inspecting the EOFs from each of the sliding data windows over time, we found that an increasing fraction of the ensemble members had basin-wide trend patterns resembling Fig. $3 \mathrm{~b}$ appearing as SIC $_{1}$ and NAO-driven dipole patterns resembling Fig. 3e appearing as $\mathbf{S I C}_{2}$. In other words, NAO-like dipole patterns clearly led the sea ice variability early in the 20th century, but became secondary to emerging sea ice trends thereafter. The preceding results thus indicate a decreasing role for the NAO in driving the leading mode of SIC variability over the North Atlantic because of the increasing importance of loss trends over the marginal ice zone. 


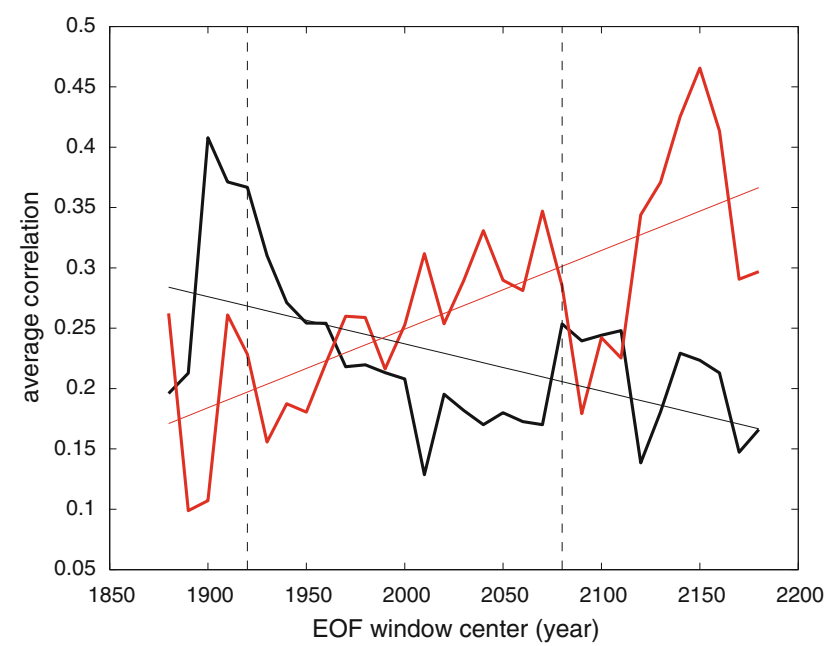

Fig. 4 For 40-year data windows centered every 10 years, the correlation $r\left(\mathrm{SLP}_{\mathrm{PC} 1}, \mathrm{SIC}_{\mathrm{PCl}}\right)$ averaged across ensemble members (black) and the correlation $r\left(\mathrm{SLP}_{\mathrm{PC} 1}, \mathrm{SIC}_{\mathrm{PC} 2}\right)$ averaged across ensemble members (red). The 1920-2080 results are based on $\mathrm{ECHAM}_{\mathrm{a}-\mathrm{c}}$ and $\mathrm{CCSM}_{\mathrm{a}-\mathrm{e}}$, and the results prior to 1920 and after 2080 are based on ECHAM $_{a-c}$ only (these years are marked by dashed vertical lines). Each time series has a least squares linear regression shown

\subsection{The 22nd century}

Into the 22nd century, the A1B scenario levels off $\mathrm{CO}_{2}$ concentrations, so the winter ice loss trends begin to slow and account for a smaller fraction of the total North Atlantic SIC variance. Figure 5a shows SIC $_{1}$ for the ECHAM $_{a-c}$ ensemble over years 2101-2200. This 22nd century leading SIC EOF is less expansive, and accounts for approximately half the variance of, its 21 st century counterpart (compare to Fig. 3a). $\mathbf{S I C}_{2}$ is still an east-west SIC dipole pattern conceptually similar to those associated with the NAO for earlier periods, and is well correlated with its corresponding NAOI (Fig. 5d). However, comparison of Figs. 1a and 5c show that this NAO-driven SIC dipole has undergone marked changes from its early 20th century counterpart in direct response to the retreated marginal ice zone. Specifically, the loading has disappeared from the east coast of Greenland up to Svalbard, and from much of the Gulf of Bothnia, which lies between Sweden and Finland. The negative center of action in the Barents Sea is greatly weakened and shifted entirely east of Novaya Zemlya, and the positive center of action near the Labrador Sea has retreated out of the Gulf of St. Lawrence and advanced into Hudson Bay and Baffin Bay.

\subsection{A multi-century perspective}

As a follow to the analysis of $50-100$ year periods given in the preceding sections, we now consider SIC and SLP variability in the longest-running ensemble member in our study-ECHAM ${ }_{b}$ which was integrated from 1860 to 2300. In this multi-century framework, SIC $_{1}$ captures declining SIC within the marginal ice zone, accounting for $79 \%$ of the total variance (Fig. 6a). The associated principal component $\left(\mathrm{SIC}_{1}\right.$, black curve in Fig. 6d) is relatively constant prior to 2000 , undergoes rapid increase from 2000 to 2100 , and slower increase from 2100 to 2300. The rapid 21 st century loss is in part related to oceanic heat transport as shown in Fig. 3b, c. Here we show that the 400-year time series of this sea ice loss principal component is well correlated $(r=0.99)$ with the global mean $2 \mathrm{~m}$ air temperature, which is one proxy for increased heat storage in the climate system (red curve, Fig. 6d).

A north-south oriented dipole of SIC appears as $\mathbf{S I C}_{2}$ (Fig. 6b), accounting for $5 \%$ of the total variance, or approximately a quarter of the variance not accounted for by the leading EOF. Given its zonally-elongated, north-tosouth dipole pattern, $\mathbf{S I C}_{2}$ captures interannual variability in the equatorward extent of the sea ice edge, where lower principal component scores correspond to more expansive sea ice advance. The associated principal component $\left(\mathrm{SIC}_{2}\right.$, black curve in Fig. 6e) is negative prior to 2000 and after 2150 , indicating that the seasonal sea ice extent is greater during times of slower ice trends. We verify this impression by calculating the first derivative of a smoothed version of $\mathrm{SIC}_{1}$, shown as the red curve in Fig. 6e. Indeed, the period with the most rapid sea ice loss (2000-2150) corresponds well with the period of lowered seasonal sea ice advance. Note that, since $\mathbf{S I C}_{2}$ is orthogonal to $\mathbf{S I C}_{1}$, the variability in sea ice advance captured by this second EOF occurs on top of the total loss trend. In other words, after 2150 , the sea ice advance was anomalously equatorward (low $\mathrm{SIC}_{2}$ ) after accounting for the overall retreat of the marginal ice zone (high $\mathrm{SIC}_{1}$ ).

The third SIC EOF ( $\mathbf{S I C}_{3}$, Fig. $6 \mathrm{cc}$ ) is an east-west dipole resembling the NAO-driven patterns described in the previous sections, but accounts for only $2 \%$ of the total variability, or $12 \%$ of the variance not accounted for by $\mathbf{S I C}_{1,2}$. The associated principal component reasonably follows the NAOI for the duration of the integration (Fig. 6f). To explain how $\mathrm{SIC}_{3}$ remains synchronized with the NAOI despite the changing position of the marginal ice zone, we note that $\mathbf{S I C}_{3}$ is approximately the union of the NAO-driven east-west SIC dipole patterns appearing in ECHAM $_{\mathrm{a}-\mathrm{c}}$ for years 1901-1950 (Fig. 1a), 2001-2099 (Fig. 3d), and 2101-2200 (Fig. 5c). As the approximate union of these EOFs, the 1860-2300 $\mathbf{S I C}_{3}$ is able to pick up east-west SIC fluctuations as the marginal ice zone retreats across the EOF. 
Fig. 5 All panels are for years 2101-2200. a The leading EOF of sea ice concentration averaged across ECHAM $_{a-c}$. b The corresponding principal component from $\mathrm{ECHAM}_{\mathrm{b}}$. c The NAO loading pattern (contours) and second EOF of sea ice concentration (shading), both averaged across ECHAM $_{\mathrm{a}-\mathrm{c}}$. d The principal components corresponding to panel $c$, taken from ECHAM (the NAOI is red)
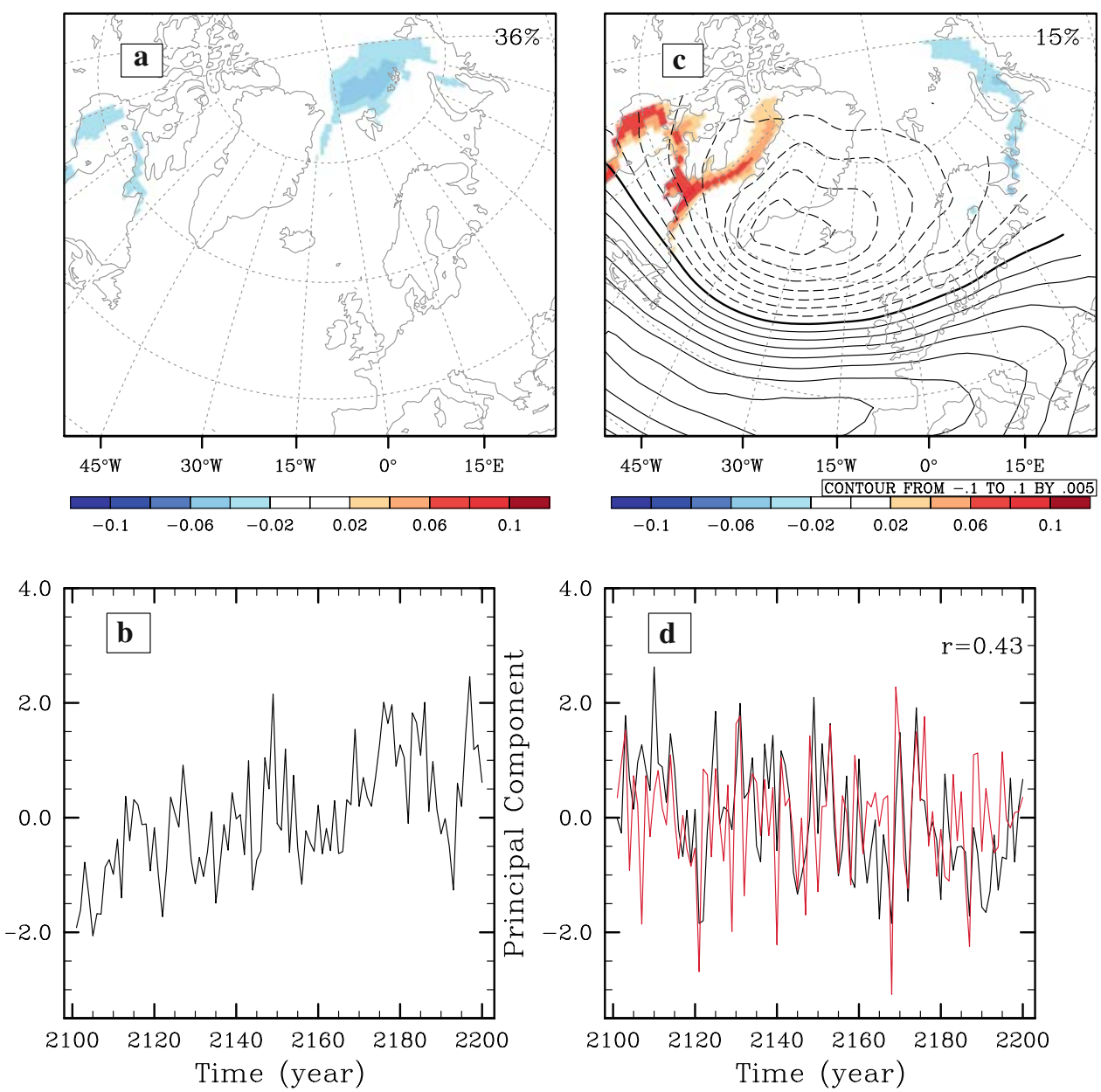

\section{Summary and discussion}

We examined the relationship between boreal winter sea ice variability and the North Atlantic Oscillation (NAO) for the time period 1860-2300. Nine ensemble members are used from two global climate models with forcing evolving from pre-industrial conditions through a scenario where carbon dioxide stabilizes at $720 \mathrm{ppm}$ by 2100 . In all centuries, the NAO generates an east-west dipole pattern of sea ice concentration (SIC) anomalies with oppositely signed centers of action over the Labrador and Barents Seas. During the positive polarity of the NAO, SIC increases over the Labrador Sea due to wind-driven equatorward advection of ice, and SIC decreases over the Barents Sea due to wind-driven poleward advection of heat within the mixed layer of the ocean.

This NAO-driven SIC variability pattern can be detected as an EOF for any sliding window over the analysis period, but is the leading EOF only in the absence of basin-wide decadal increases or decreases in SIC. The equatorward extent of the centers of action in the NAO-driven SIC dipole lessened in the simulations as the sea ice edge retreated poleward, and the Barents Sea center of action weakened. The NAO-driven SIC dipole accounted for a markedly varying fraction of the total sea ice variability depending on the strength of the forced sea ice extent trend. In runs for the first half of the 20th century and under 1990 control conditions, the NAO-driven SIC pattern accounted for almost a third of the total SIC variance. In 21st century results, the equatorward extent of the NAO-driven SIC pattern lessened, and its Barents Sea center of action weakened. From a multi-century perspective spanning 1860-2300, the leading sea ice EOF captured the overall ice loss, the second EOF related the interannual ice extent variability to the rate of ice loss, and the NAO-driven SIC pattern appeared as the third EOF, accounting for only $2 \%$ of the total SIC variance.

The recovery of an NAO-driven SIC variability pattern using the entire 1860-2300 simulation is quite remarkable given the basin-wide changes associated with retreat of the sea ice edge and given the orthogonality constraint of the statistical method used. Although it represents a small fraction of the total variance from a multi-century perspective, the imprint of the NAO on sea ice is robustly present even under substantial projected climate change. 

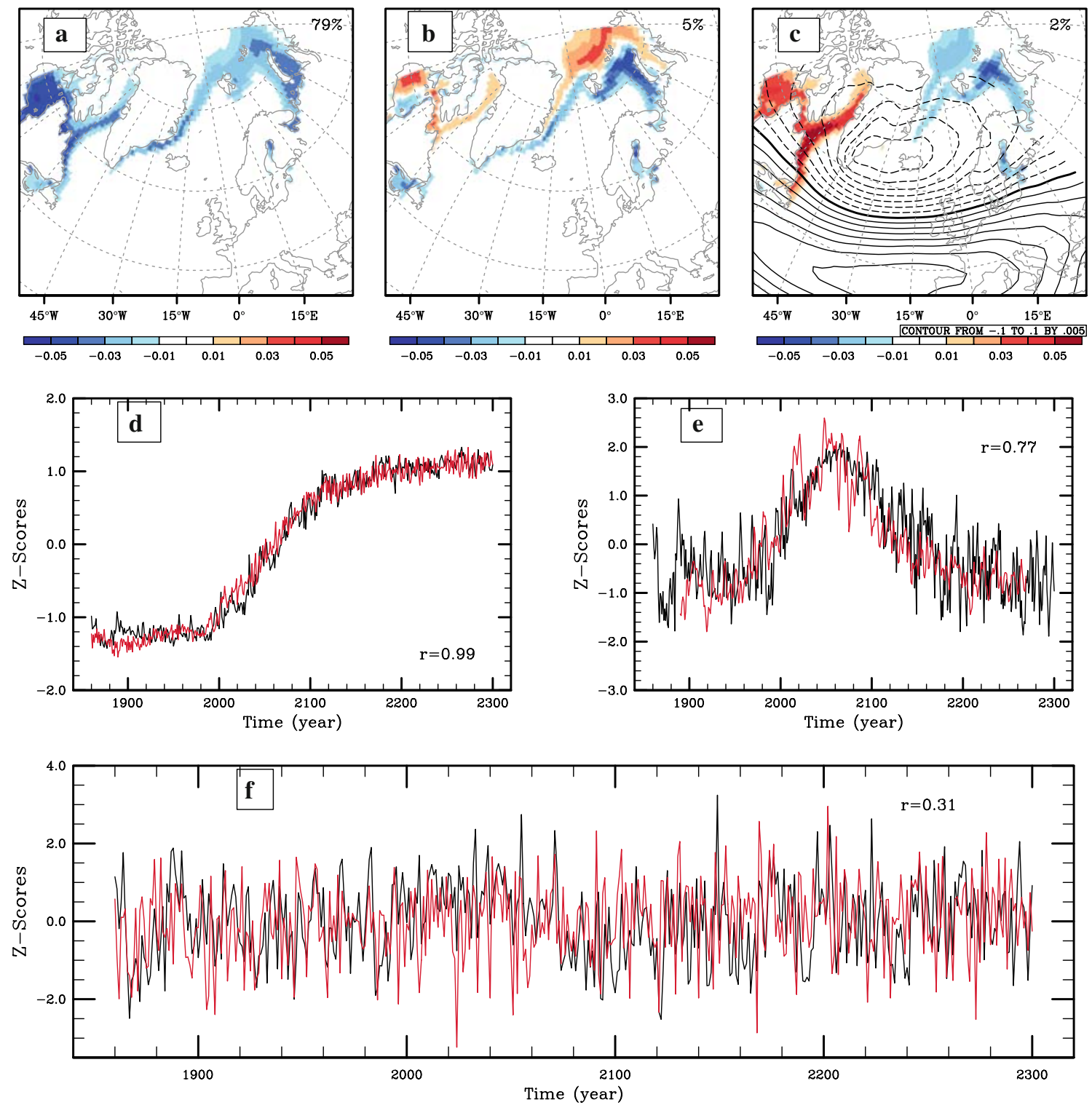

Fig. 6 All panels are for 1860-2300 in ECHAM . Sea ice concentration (a) EOF 1, (b) EOF 2, and (c) EOF 3 (shading) with the loading pattern of the NAO (contours). d The principal component (PC) of sea ice EOF 1 (black) and the mean northern hemisphere $2 \mathrm{~m}$

As discussed in the Introduction, observational studies covering the second half of the 20th century found an NAOdriven dipole as the leading pattern of SIC variability (Deser 2000), and several studies concluded that trends in the NAO or NAM may have amplified winter sea ice retreat. When the available years of the 21 st century are considered, however, an overall sea ice retreat trend is emerging on top of which the NAO provides east-west dipole SIC variability (Deser and Teng 2008). In darkness, boreal winter sea ice is not subject to positive ice-albedo feedback. Based on the projection to 2300 examined here, boreal winter sea ice will retreat poleward but not leave the regions influenced by NAO-related circulation anomalies. This amounts to a air temperature (red). e The PC of sea ice EOF 2 (black) and the time rate of change of EOF 1 (red). $\mathbf{f}$ The PC of sea ice EOF 3 (black) and the NAO index $(r e d)$

poleward shift in the centers of action of the NAO-driven SIC dipole EOF, which has implications for the patterns of ice-to-atmosphere feedback that will be present in the system as it undergoes anthropogenic change.

Acknowledgments This research was supported by NSF Grant ATM-0612779 and NOAA Grant NA06OAR4310149. The manuscript was improved by discussions with Cecilia Bitz and Elizabeth Hunke, as well as comments from two anonymous reviewers.

Open Access This article is distributed under the terms of the Creative Commons Attribution Noncommercial License which permits any noncommercial use, distribution, and reproduction in any medium, provided the original author(s) and source are credited. 


\section{References}

Alexander MA, Bhatt US, Walsh JE, Timlin MS, Miller JS, Scott JD (2004) The atmospheric response to realistic Arctic sea ice anomalies in an AGCM during winter. J Clim 17:890-905

Arzel O, Fichefet T, Goose H (2006) Sea ice evolution over the 20th and 21 st centuries as simulated by current AOGCMs. Ocean Modell 12:401-415

Cavalieri DJ (2002) A link between Fram Strait sea ice export and atmospheric planetary wave phase. Geophys Res Lett 29. doi: 10.1029/2002GL014684

Comiso JC (2006) Abrupt decline in arctic winter sea ice cover. Geophys Res Lett 33. doi:10.1029/2006GL027341

Dai A, Hu A, Heehl GA, Washington WM, Strand WG (2005) Atlantic thermohaline circulation in a coupled general circulation model: unforced variations versus forced changes. J Clim 18:3270-3293

Deser C (2000) On the teleconnectivity of the "Arctic Oscillation". Geophys Res Lett 27:779-782

Deser C, Teng H (2008) Evolution of Arctic sea ice concentration trends and the role of atmospheric circulation forcing, 19792007. Geophys Res Lett 35. doi:10.1029/2007GL032023

Deser C, Magnusdottir G, Saravanan R, Phillips AS (2004) The effects of North Atlantic SST and sea-ice anomalies on the winter circulation in CCM3. Part II: direct and indirect components of the response. J Clim 17:877-889

Deser C, Tomas RA, Peng S (2007) The transient atmospheric circulation response to North Atlantic SST and sea ice anomalies. J Clim 20:4751-4767

Dickson RR, Osborn TJ, Hurrell JW, Meincke J, Blindheim J, Adlandsvik B, Jinje T, Alekseev G, Maslowski W (2000) The Arctic Ocean response to the North Atlantic Oscillation. J Clim 13:2671-2696

Eisenman I, Untersteiner N, Wettlaufer JS (2007) On the reliability of simulated Arctic sea ice in global climate models. Geophys Res Lett 34. doi:10.1029/2007GL029914

Flatau MK, Talley L, Niller PP (2003) The North Atlantic Oscillation, surface current velocities, and SST changes in the subpooloar North Atlantic. J Clim 16:2355-2369

Francis JA, Hunter E (2004) Drivers of declining sea ice extent in the Arctic winter: a tale of two seas. Geophys Res Lett 61:145160

Goose H, Holland MM (2005) Mechanisms of decadal Arctic climate variability in the Community Climate System Model, Version 2 (CCSM2). J Clim 18:3552-3570

Hilmer M, Jung T (2000) Evidence for a recent change in the link between the North Atlantic Oscillation and Arctic sea ice export. Geophys Res Lett 27:989-992

Hu A, Rooth C, Bleck R, Deser C (2002) Nao influence on sea ice extent in the eurasian coastal region. Geophys Res Lett 29. doi: 10.1029/2001GL014293

Hurrell JW (1995) Decadal trends in the North Atlantic Oscillation: regional temperatures and precipitation. Science 269:676-679

Johannessen OM, Bengtsson L, Miles MW, Kuzmina SI, Semenov VA, Alekseev GV, Nagurnyi AP, Zakharov VF, Boblyev LP, Petterson LH, Hasselmann K, Cattle HP (2004) Arctic climate change: observed and modelled temperature and sea-ice variability. Tellus 56:328-341

Jung T, Hilmer M (2001) The link between the North Atlantic Oscillation and Arctic sea ice export through the Fram Strait. J Clim 14:3932-3943

Jungcalus JH, Haak H, Latif M, Mikolajewicz U (2005) Arctic-North Atlantic interactions and multidecadal variability of the Meridional Overturning Circulation. J Clim 18:4013-4031
Jungcalus JH, Botzet M, Haak H, Keenlyside N, Luo JJ, Latif M, Marotzke J, Mikolajewicz U, Roeckner E (2006) Ocean circulation and tropical variability in the coupled model ECHAM5/MPI-OM. J Clim 19:3952-3972

Kaihatu JM, Handler RA, Marmorino GO, Shay LK (1998) Empirical orthogonal function analysis of ocean surface currents using comples and real-vector methods. J Atmos Ocean Technol 15:927-941

Kvamsto NG, Skeie P, Stephenson DB (2004) Impact of Labrador sea-ice extent on the North Atlantic Oscillation. Int J Climatol 24:603-612

Kwok R (2000) Recent changes in Arctic Ocean sea ice motion associated with the North Atlantic Oscillation. Geophys Res Lett 27:775-778

Kwok R, Rothrock DA (1999) Variability of Fram Strait ice flux and North Atlantic Oscillation. J Geo Res 104:5177-5189

Lindsay RW, Zhang J (2005) The thinning of Arctic sea ice, 19982003: have we passed a tipping point? J Clim 18:4879-4894

Liu J, Curry JA (2004) Recent Arctic sea ice variabilty: connections to the Arctic Oscillation and the ENSO. Geophys Res Lett 31. doi:10.1029/2004GL019858

Magnusdottir G, Deser C, Saravanan R (2004) The effects of North Atlantic SST and sea ice anomalies on the winter circulation in CCM3. Part I: main features and storm track charactersitcs of the response. J Clim 17:857-876

Maslanik J, Drobot S, Fowler C, Emery W, Barry R (2007) On the Arctic climate paradox and the continuing role of atmospheric circulation in affecting sea ice conditions. Geophys Res Lett 34 doi: $10.1029 / 2006$ GL028269

Meehl GA, Washington WM, Santer BD, Collins WD, Arblaster JM, Hu A, Lawrence DM, Teng H, Buja LE, Strand WG (2006) Climate change in the 20th and 21st centuries and climate change commitment in the CCSM3. J Clim 19:25972616

Miller RL, Schmidt GA, Shindell DT (2006) Forced annular variations in the 20th century Intergovernmental Panl on Climate Change Fourth Assessment Report models. Geophys Res Lett 111. doi:10.1029/2005JD006323

Mysak LA, Venegas SA (1998) Decadal climate oscillations in the Arctic: a new feedback loop for atmosphere-ice-ocean interactions. Geophys Res Lett 25:3607-3610

Nakicenovic N, Swart R (2000) Special report on emissions scenarios. Cambridge University Press, Cambridge

Parkinson CL, Vinnikov KY, Cavalieri DJ (2006) Evaluation of the simulation of the annual cycle of Arctic and Antarctic sea ice coverages by 11 major global climate models. J Geo Res 111 . doi: $10.1029 / 2005$ JC003408

Rigor IG, Wallace JM, Colony RL (2002) Response of sea ice to the arctic oscillation. J Clim 15:2648-2663

Rothrock DA, Zhang J (2005) Arctic ocean sea ice volume: what explains its recent depletion? J Geo Res 110. doi: 10.1029/2004JC002282

Serreze MC, Holland MM, Stroeve J (2007) Perspectives on the arctic's shrinking sea-ice cover. Science 315:1533-1536

Sorteberg A, Kvingedal B (2006) Atmospheric forcing of the Barents Sea winter ice extent. J Clim 19:4772-4784

Stephenson DB, Pavan V, Collins M, Junge MM, Quadrelli R (2006) North Atlantic Oscillation response to transient greenhouse gas forcing and the impact on European winter climate: a CMIP2 multi-model assessment. Clim Dyn 27:401-420

Stroeve J, Holland MM, Meier W, Scambos T, Serreze M (2007) Arctic sea ice decline: faster than forecast. Geophys Res Lett 34. doi:10.1029/2007GL029703

Ukita J, Honda M, Nakamura H, Tachibana Y, Cavlieri DJ, Parkinson CL, Koide H, Yamamoto K (2007) Northern Hemisphere sea ice 
variability: lag structure and its implications. Tellus A 59:261272. doi:10.111/j.1600-0870.2006.0223.x

Venegas SA, Mysak LA (2000) Is there a dominant timescale of natural cliamte variability in the arctic? J Clim 13:3412-3434

Vinje T (2001) Anomalies and trends in sea-ice extent and atmospheric circulation in the Nordic Seas during the period 1864-1998. J Clim 14:3503-3517

Wang J, Ikeda M (2000) Arctic Oscillation and Arctic sea-ice oscillation. Geophys Res Lett 27:1287-1290
Zhang X, Walsh JE (2006) Toward a seasonally ice-covered Arctic Ocean: scenarios from the IPCC AR4 model simulations. J Clim 19:1730-1747

Zhang J, Rothrock D, Stelle M (2000) Reent changes in Arctic sea ice: the interplay between ice dynamics and thermodynamics. J Clim 13:3099-3114

Zhang X, Ikeda M, Walsh JE (2003) Arctic sea ice and freshwater changes driven by the atmoshperic leading mode in a coupled sea ice-ocen model. J Clim 16:2159-2177 